\title{
Lebensgefährliche Zahnstocher
}

\section{Unter verschluckten Fremdkörpern gibt es harmlose und weniger harm- lose. Mit verschluckten Zahnstochern ist eindeutig nicht zu spaßen.}

— Ein 65-jähriger Mann wurde wegen Kurzatmigkeit und Bauchschmerzen ins Krankenhaus aufgenommen. Aus der Vorgeschichte waren ein chronischer Alkoholmissbrauch und ein Herzgeräusch bekannt. Die Untersuchung ergab ein Holosystolikum mit punctum maximum an der Herzspitze, inspiratorische feuchte Rasselgeräusche, eine absolute Arrhythmie und einen Druckschmerz im rechten Oberbauch mit einem fraglich positiven Murphy-Zeichen.

Im Labor waren eine Leukozytose und Entzündungszeichen vorhanden, die Oberbauchsonografie ergab erweiterte Lebervenen und eine normale Gallenblasenwand.

Echokardiografisch fand man eine schwere Mitralinsuffizienz mit dem Ver-

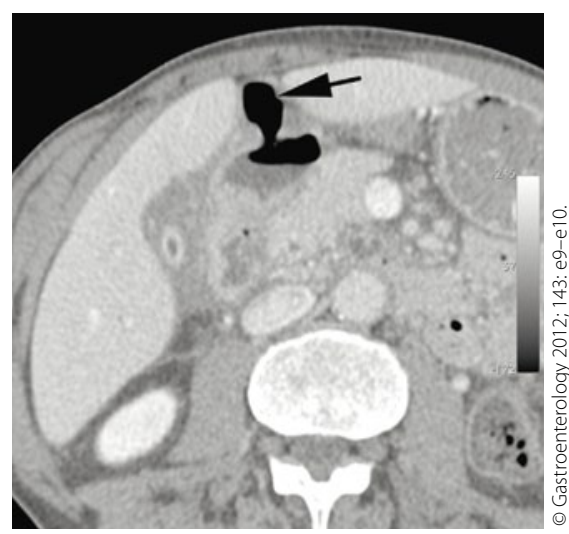

Perforation des Dünndarms im CT (Pfeil).

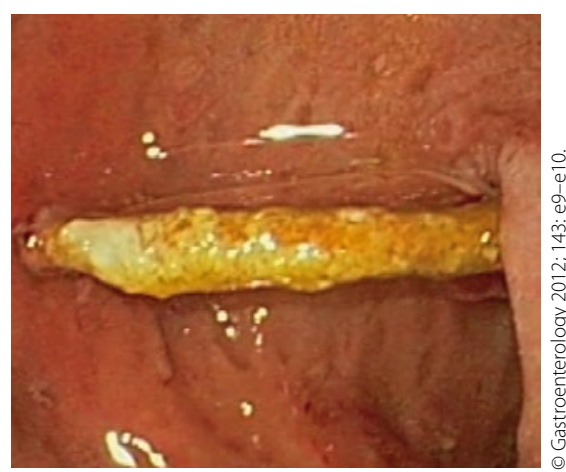

Das Corpus delicti in der Gastroskopie. dacht auf einen Abriss von Sehnenfäden der Mitralklappe. Unter der Diagnose einer Herzinsuffizienz wurde der $\mathrm{Pa}$ tient einschlägig behandelt, worauf sich sein Befinden auch besserte.

Aufgrund der unverändert vorhandenen rechtsseitigen Oberbauchschmerzen und des nun klar positiven Murphy-Zeichens am fünften stationären Tag bei fortbestehender entzündlicher Laborkonstellation wurde eine Computertomografie des Abdomens durchgeführt (obere Abb.). Hier fand man Hinweise auf eine Perforation des Dünndarms (obere Abb., Pfeil) in Verbindung mit einer Cholezystitis. Aufgrund des reduzierten Allgemeinzustandes entschloss man sich zunächst zu einer konservativen Therapie mit Antibiotika und Protonenpumpenblocker. Die Serologie auf H. pylori war negativ.

Der Patient wurde gebessert entlassen, man führte aber sechs Wochen später doch eine Gastroskopie durch. Hier fand sich ein an beiden Enden spitzer Zahnstocher, der die Gallenblasenwand perforiert hatte (untere Abb.). Der $6 \mathrm{~cm}$ lange Zahnstocher konnte endoskopisch entfernt werden, die Perforationsstelle wurde mit einem Clip abgedichtet.

- N. Lanthier et al.

An unusual cause of cholecystitis. Gastroenterology 2012; 143: e9-e10.

\section{Kommentar}

Die Ingestion von Fremdkörpern ist ein gängiges Problem bei Kindern, alkoholkranken und psychiatrischen Patienten, Personen mit Zahnersatz und älteren Patienten. Eine sekundäre Cholezystitis durch die Ingestion und Perforation eines Fremdkörpers wurde bislang noch nicht berichtet.

Verschluckte Zahnstocher sind durchaus gefährliche Objekte: in einem systematischen Review an 57 Patienten wurde in nur 14\% Fälle das Objekt mit Bildgebung entdeckt. In über der Hälfte der Fälle konnte die Diagnose erst mittels Laparotomie gestellt werden, wobei die Gesamtmortalität immerhin 18\% betrug.

H. S. FÜESSL =

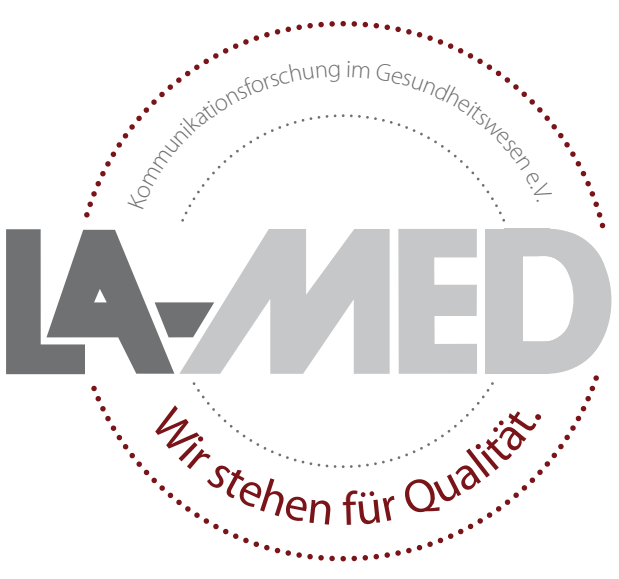

\section{Sie lesen Qualität}

Damit das auch so bleibt, befragen wir Sie in Kooperation mit tns infratest in den nächsten Wochen.

Ihr Urteil ist uns wichtig. Bitte nehmen Sie teil! 